\title{
Physiology and predictors of impaired gas exchange in infants with bronchopulmonary dysplasia
}

*Jenny Svedenkrans PhD, ${ }^{\mathrm{a},{ }^{*}, \mathrm{c}}$, *Benjamin Stoecklin $\mathrm{MD}^{\mathrm{a}, \mathrm{d}, \mathrm{e}}$, J. Gareth Jones FRCP ${ }^{\mathrm{f}}$, Dorota A. Doherty $\mathrm{PhD}^{\mathrm{g}}$, J. Jane Pillow ${ }^{\mathrm{a}, \mathrm{d}} \mathrm{PhD}$

\author{
Affiliations: \\ ${ }^{a}$ Centre for Neonatal Research and Education, University of Western Australia, Perth, \\ Australia; \\ ${ }^{\mathrm{b}}$ Department of Clinical Science, Intervention and Technology, Division of Pediatrics, \\ Karolinska Institutet, Stockholm, Sweden; \\ ${ }^{\mathrm{c}}$ Department of Neonatal Medicine, Karolinska University Hospital, Stockholm, Sweden; \\ ${ }^{\mathrm{d}}$ School of Human Sciences, University of Western Australia, Perth, Australia; \\ ${ }^{e}$ Neonatal Clinical Care Unit, King Edward Memorial Hospital, Perth, Australia; \\ ${ }^{\mathrm{f}}$ University Department of Anaesthesia, Addenbrooke's Hospital, Cambridge, United \\ Kingdom \\ ${ }^{\mathrm{g}}$ Division of Obstetrics and Gynaecology, Medical School, University of Western Australia, \\ Perth, Australia \\ *joint first authors
}

Address correspondence to:

Assoc Prof Jane Pillow,

School of Human Sciences,

M309 The University of Western Australia,

35 Stirling Highway, Crawley 6009, Western Australia, Australia

Jane.pillow@uwa.edu.au

Ph: +61864883318

Funding source: All phases of this study were supported by the University of Western Australia and the Women and Newborn Health Service of Western Australia. Funded by National Health and Medical Research Council (NHMRC) of Australia (GRT1047689, GRT1057514) and the Metropolitan Health Research Infrastructure Fund (MHRIF). Prof Pillow was supported by a NHMRC Senior Research Fellowship (GRT1077691). Dr Svedenkrans was supported by The Swedish Society of Medicine, The Samaritan Foundation, The Princess Lovisa Memory Foundation, The Society of Child Care (Sällskapet Barnavård), and The Fernstrom Foundation. Dr Stoecklin was supported by the Swiss National Science Foundation (P2BSP3_158837) and a Research Training Program scholarship, The University of Western Australia.

Short running head: Physiology of impaired gas exchange in BPD

Descriptor: 14.3

Manuscript Body Word Count: 3639

\section{At a Glance Commentary:}

Scientific Knowledge on the Subject: Assessment of impaired gas exchange may provide a continuous outcome measure for sensitive and equitable determination of severity of bronchopulmonary dysplasia (BPD). Previous gas exchange studies in BPD infants used 
small cohorts and targeted moderate-severe BPD. These studies show right shift of the peripheral oxyhemoglobin saturation $\left(\mathrm{SpO}_{2}\right)$ versus inspired oxygen partial pressure $\left(\mathrm{P}_{\mathrm{I}} \mathrm{O}_{2}\right)$ curve and reduced ventilation-perfusion ratio reliably predict hypoxaemia in preterm infants breathing air, and further, that many infants also have a right-left shunt.

What This Study Adds to the Field: We provide measures of right shift, ventilation/perfusion and shunt, across the full spectrum of lung disease in a large $(n=219)$ group of preterm infants. Shift increases and ventilation/perfusion decreases with increased severity of BPD as defined by the NIH classification of BPD. Shunt is primarily a feature of infants with moderate-severe BPD who require supplemental oxygen. Non-invasive bedside assessment of shift, ventilation/perfusion and shunt provide physiological continuous outcome measures of severity of respiratory disease in very preterm infants with/without BPD independent of altitude and unit practices. Routine analysis of the $\mathrm{SpO}_{2} / \mathrm{P}_{\mathrm{I}} \mathrm{O}_{2}$ curve may improve accuracy of BPD severity classification and provide a sensitive continuous outcome measure for clinical trials evaluating pulmonary outcomes.

*This article has an online data supplement, which is accessible from this issue's table of content online at www.atsjournals.org

\section{Contributors' Statements:}

Dr J Svedenkrans collected and analysed the data, interpreted the data, drafted the initial manuscript, performed literature search, drafted the figures, and approved the final manuscript as submitted. Dr B Stoecklin assisted with the REDCap database design and development, collected and analysed the data, interpreted the data, reviewed and revised the manuscript, and approved the final manuscript as submitted. Prof JG Jones developed the algorithms used for the calculation of shunt, shift and $\mathrm{V}_{\mathrm{A}} / \mathrm{Q}$, reviewed and revised the manuscript, and approved the final manuscript as submitted. Prof D Doherty contributed to the overall study design and successful funding, advised on the statistical approach, reviewed the statistical analyses, reviewed and approved the final manuscript as submitted. Assoc/Prof J J Pillow was the principal investigator obtaining funding, leading study design including development of the REDCap database, obtained the study funding, verified all statistical calculations, interpreted the data, critically reviewed and revised the manuscript, and approved the final manuscript as submitted. 


\begin{abstract}
Rationale

A sensitive outcome measure for infants with bronchopulmonary dysplasia would facilitate clinical benchmarking, enhance epidemiological understanding, evaluation of clinical interventions, and outcome prediction.
\end{abstract}

\title{
Objectives
}

Non-invasive assessment of pulmonary gas exchange in preterm infants with and without bronchopulmonary dysplasia to grade disease severity and to identify determinants of impaired gas exchange.

\section{Methods}

Prospective observational study in very preterm infants. Inspired oxygen pressure was decreased stepwise to achieve oxygen saturation from $95-86 \%$. Right shift, ventilation/perfusion ratio and right-left shunt were derived from the resulting oxygen dissociation curve and compared to current disease severity classification. Potential determinants of shift, ventilation/perfusion and shunt were identified using principal components analysis and multiple linear regression.

\section{Measurements and Main Results}

219 infants with median (IQR) gestation of $28^{0}\left(26^{0}-29^{0}\right)$ weeks had a valid study at $35^{4}\left(34^{7}-39^{3}\right)$ weeks' postmenstrual age. Shift increased and ventilation/perfusion decreased as severity of bronchopulmonary dysplasia increased. Infants with moderate-severe disease also had increased shunt. Extent of impaired gas exchange overlapped between severity groups. Infants requiring mechanical support but no supplemental oxygen at 36 weeks' postmenstrual age had similar values of shift, ventilation/perfusion and shunt to preterm infants without bronchopulmonary dysplasia. Lower gestation and increased duration of invasive ventilation independently predicted increased shift, decreased ventilation/perfusion and increased shunt. Shift was the most sensitive and specific index of the severity of bronchopulmonary dysplasia.

\section{Conclusions}

Most infants with bronchopulmonary dysplasia have impaired oxygenation quantified by a simple, sensitive bedside testShift of the $\mathrm{SpO}_{2} / \mathrm{P}_{\mathrm{I}} \mathrm{O}_{2}$ curve may be useful for prediction and measurement of preterm infant respiratory outcomes.

Abstract Word Count: 250

Key words for indexing: infant, premature; ventilation, mechanical; oximetry; ventilation-perfusion ratio; oxygen inhalation therapy. 


\section{Introduction}

Bronchopulmonary dysplasia (BPD) is a respiratory disorder in preterm infants characterised by impaired development of alveoli and pulmonary capillaries. Impaired development of the lung parenchyma may have life-long implications for respiratory health (1). In this regard, and oddly without mentioning arterial oxyhemoglobin saturation $\left(\mathrm{SaO}_{2}\right)$, the National Institute of Health $(\mathrm{NIH})$ defined BPD in 2001 as a need for supplemental oxygen for at least 28 days. Again without mention of $\mathrm{SaO}_{2}$, the $\mathrm{NIH}$ defined severity of BPD in very preterm infants by the level of supplemental oxygen required at 36 weeks' postmenstrual age (PMA). The definition of severe BPD includes a need for pressure support regardless of $\mathrm{P}_{\mathrm{I}} \mathrm{O}_{2}$. The odd conclusion is that following these criteria, infants breathing air have mild $\mathrm{BPD}$; moderate $\mathrm{BPD}$ is a $\mathrm{P}_{\mathrm{I}} \mathrm{O}_{2}$ of 22-29 $\mathrm{kPa}$, and severe $\mathrm{BPD}$ is a $\mathrm{P}_{\mathrm{I}} \mathrm{O}_{2} \geq 30 \mathrm{kPa}$ or pressure respiratory support, even without supplemental oxygen (2).

Walsh and colleagues added another confusing dimension by proposing an alternative "physiological" BPD classification (3), that ultimately defined $\mathrm{BPD}$ as "a $\mathrm{SpO}_{2} \geq 90 \%$ at $36 \mathrm{w}$ PMA (4)"; confusing because $\mathrm{SpO}_{2}$ in healthy infants is $\geq 96 \%$. Hence the Walsh definition misclassifies infants with a mild impairment of oxygenation as normal.

More recently, a NICHD workshop on BPD in 2016 proposed a revised definition of BPD (5). However, the suggested definition of BPD continues to define BPD by its treatment rather than by functional or pathophysiological basis, and does not address the limitations of the old 2001 definition outlined above.

An alternative, non-invasive approach for assessing pulmonary outcomes after preterm birth measures $\mathrm{SpO}_{2}$ when $\mathrm{P}_{\mathrm{I}} \mathrm{O}_{2}$ is reduced stepwise, and from the shape and position of the $\mathrm{SpO}_{2}$ vs $\mathrm{P}_{\mathrm{I}} \mathrm{O}_{2}$ curve derives the right shift from the position of the oxyhemoglobin dissociation curve, reduced ventilation/perfusion ratio $\left(\mathrm{V}_{\mathrm{A}} / \mathrm{Q}\right)$, and shunt (Figure 1) $(6,7)$. This approach was initially described in 1993,(6) then first applied to neonates in 2001(8). Subsequently, shift of the $\mathrm{SpO}_{2} \mathrm{vs}_{\mathrm{I}} \mathrm{O}_{2}$ curve was used to determine the $\mathrm{P}_{\mathrm{I}} \mathrm{O}_{2}$ needed to achieve a $\mathrm{SpO}_{2}$ between $86 \%$ and $94 \%$, as an objective measure of BPD severity in 
infants with moderate to severe BPD (9). Previous studies in preterm infants are limited by the small cohort size ( $\leq 32$ infants) (9-12), a focus on infants with moderate to severe BPD,(9-11) and compensation for adult rather than fetal hemoglobin.(9-12). Full utility and application of the $\mathrm{SpO}_{2} \mathrm{vs}_{\mathrm{I}} \mathrm{O}_{2}$ approach requires application of the methodology across the full range of severity of BPD.

We derived the right shift of the $\mathrm{SpO}_{2} \mathrm{vs}_{\mathrm{I}} \mathrm{O}_{2}$ curve, reduced $\mathrm{V}_{\mathrm{A}} / \mathrm{Q}$, and right to left shunt in a large cohort of preterm infants representing the NICHD spectrum of BPD severity: we used paired measurements of $\mathrm{SpO}_{2}$ and $\mathrm{PIO}_{2}$ at 36 weeks' postmenstrual age in 219 infants less than 32 weeks' gestation. We ascertained the factors that might influence impaired gas exchange at 36 weeks' postmenstrual age. We hypothesised that a) this approach would highlight the inconsistencies between the NIH BPD classification levels and functional impairment of oxygenation; and that b) gestation and duration of invasive ventilation would be the primary independent factors influencing shift of the $\mathrm{SpO}_{2}$ vs. $\mathrm{P}_{1} \mathrm{O}_{2}$ curve at $36 \mathrm{w}$ postmenstrual age, whilst the presence of significant right to left shunt would be restricted to infants with moderate to severe BPD as defined by the NIH (2). Some of the results of these studies were reported previously in the form of abstracts $(13,14)$.

\section{Methods}

\section{Study design and ethics approval}

This study was a prospective evaluation of BPD severity in unsedated preterm infants at $36 \mathrm{w}$ postmenstrual age. The study was approved by the Women and Newborn Health Service Human Research Ethics Committee (HREC: 1883EW and 20130193EW) and the University of Western Australia (RA/4/1/5942 and RA/4/1/426). 


\section{Study participants}

Preterm infants were recruited from the Neonatal Critical Care Unit at King Edward Memorial Hospital for Women in Perth, Western Australia (KEMH) (Figure 2). Eligible infants were those born at KEMH before $32 \mathrm{w}$ gestation between $21^{\text {st }}$ of July, 2013 and $8^{\text {th }}$ of January, 2017 with informed consent from a parent or guardian. All included infants were a part of the Preterm Infant Functional and Clinical Outcomes (PIFCO) study (ACTRN126130010627181). Infants were excluded if they had a major congenital malformation.

\section{Outcome assessment}

Infants were tested at $36 \mathrm{w}$ PMA or immediately prior to hospital discharge, whichever occurred sooner. Infants who were intubated, or clinically unstable at $36 \mathrm{w}$ PMA were tested within three weeks, as soon as clinical instability had resolved. Infants were studied supine during sleep, or during quiet consciousness.

\section{Paired measurements of $\mathrm{SpO}_{2}$ and $\mathrm{P}_{1} \mathrm{O}_{2}$}

All studies were obtained at sea level at which the percentage of inspired oxygen closely approximates $\mathrm{P}_{\mathrm{I}} \mathrm{O}_{2}(\mathrm{kPa})$. Inspired oxygen concentration was measured using a calibrated oxygen analyser (Model: AX300, Teledyne Analytical Instr. California). $\mathrm{SpO}_{2}$ was measured from the infant's right hand (MasimoSET® Radical-7"TM, Masimo Corporation, Frenchs Forest/NSW); a valid $\mathrm{SpO}_{2}$ measurement was defined as a good pulse wave form on the monitor without movement artefact. Measurements of $\mathrm{SpO}_{2}$ and $\mathrm{P}_{\mathrm{I}} \mathrm{O}_{2}$ were recorded digitally (Powerlab, ADInstruments, Bella Vista, NSW) and monitored and analysed within LabChart (v7, ADInstruments).

The test was usually performed using a head box with a continuous fresh gas flow of $6 \mathrm{~L} / \mathrm{min}$ commencing at the prescribed $\mathrm{P}_{\mathrm{I}} \mathrm{O}_{2}$. Infants receiving CPAP or humidified high flow with supplemental oxygen above $25 \mathrm{kPa}$ were tested bedside using adjustments to the air/oxygen blender whilst continuing on the prescribed respiratory support with a closed mouth. 
$\mathrm{P}_{\mathrm{I}} \mathrm{O}_{2}$ was reduced in $\sim 5$ steps of 1-3 kPa, to achieve $\mathrm{SpO}_{2}$ ranging from $\sim 95-86 \%$. Average $\mathrm{SpO}_{2}$ and $\mathrm{PIO}_{2}$ were determined from a one minute recording obtained four minutes after each change in $\mathrm{P}_{\mathrm{I}} \mathrm{O}_{2}$. $\mathrm{PIO}_{\mathrm{I}}$ was decreased below $21 \mathrm{kPa}$ for infants with a $\mathrm{SpO}_{2}$ of $\geq 90 \%$ in air, by mixing air $\left(20 \cdot 8 \mathrm{kPa} \mathrm{O}_{2}\right)$ with a mixture of $14 \mathrm{kPa}$ oxygen in nitrogen (BOC, Perth, Western Australia, Australia). The lowest permissible $\mathrm{P}_{\mathrm{I}} \mathrm{O}_{2}$ and $\mathrm{SpO}_{2}$ were $14 \mathrm{kPa}$ and $86 \%$ respectively. Hemoglobin was determined from a capillary or venous blood gas obtained within three days of the study.

The $\mathrm{SpO}_{2}$ vs $\mathrm{P}_{\mathrm{I}} \mathrm{O}_{2}$ curve was plotted from paired values of $\mathrm{SpO}_{2}$ and $\mathrm{P}_{\mathrm{I}} \mathrm{O}_{2}$ and compared to the expected $\mathrm{SpO}_{2}$ vs $\mathrm{PIO}_{2}$ curve, using the neonatal oxyhemoglobin dissociation curve as reference (see Figure 1). Shift, $\mathrm{V}_{\mathrm{A}} / \mathrm{Q}$ and right to left shunt were derived using the Lockwood algorithm, which derives results for each dataset from both 1) a two compartment model (shunt, shift and $\mathrm{V}_{\mathrm{A}} / \mathrm{Q}$ of a single homogeneous ventilated compartment) and 2) a three compartment model (shunt, $\mathrm{V}_{\mathrm{A}} / \mathrm{Q}$ for each of two homogeneous ventilated compartments and the relative perfusion of each ventilated lung region) (15). The current hemoglobin level was incorporated in the computations.

\section{Data management and statistical methods}

Recruitment and study data were collected prospectively and managed using Research Electronic Data Capture (REDCap) software hosted at The University of Western Australia (16). Analysis included all infants with a valid study.

Descriptive statistics are presented as mean (SD) for variables with normal distribution and with median (IQR) for variables without normal distribution. Infant characteristics (excluded and tested) were performed using t-test, Mann-Whitney U-test and chi $^{2}$-test, as appropriate. The relation between the outcome variables (shift, $\mathrm{V}_{\mathrm{A}} / \mathrm{Q}$ and shunt) and the infant's NIH BPD classification were determined using one way ANOVA. The threshold level that optimised sensitivity and specificity for defining mild, moderate or severe BPD was calculated from a receiver operating curve as $\sqrt{(1-\text { Sensitivity })^{2}+(1-\text { Specificity })^{2}}$. 
Potential explanatory variables for the outcome variables of shift, $V_{A} / Q$ and shunt were examined for normal distribution (Shapiro-Wilk) and collinearity (Variance Inflation Factor). Skewed data were transformed to meet assumptions required for linear regression. Postnatal explanatory variables collinear with maturity at birth were regressed against gestation, and the unstandardized residuals saved as an independent linear measure of the variable of interest.

Potential independent perinatal factors influencing shift, $\mathrm{V}_{\mathrm{A}} / \mathrm{Q}$ and shunt were identified from univariate regression. Principal component analysis was used to examine the key variance factors (Eigenvalue $>1 \cdot 0)$ within the cohort and to address residual multiple collinearity between potential explanatory variables. The factor with the highest score of the rotated component matrix and least overlap with other factors was selected for stepwise multiple linear regression. Model fit is reported as adjusted $\mathrm{R}^{2}$. Effect size is reported as B $(95 \% \mathrm{CI})$. Statistical significance was defined as $\mathrm{p}<0 \cdot 05$. Data were analysed using SPSS (v25; IBM Corp, USA).

\section{Results}

\section{Cohort description}

The flow pathway describing eligibility, recruitment and enrolment into the study is shown in Figure 2. Characteristics of eligible, recruited and studied infants are shown in Table 1. Studied infants are further characterised according to 2001 NIH BPD severity classification in Table 2.

\section{Relation of oxygen dissociation curve outcome variables to NIH BPD Severity Classification}

Tests were completed within 25-30 minutes (5 steps of 5 min each). A valid test was obtained from each infant tested. Shift, $\mathrm{V}_{\mathrm{A}} / \mathrm{Q}$ and shunt derived from the neonatal oxyhemoglobin curve are shown according to NIH BPD classification in Figure 3; the median (IQR) shift, $\mathrm{V}_{\mathrm{A}} / \mathrm{Q}$ and shunt are presented in Table E1 (online data supplement). Data from all included infants were best fitted to a two compartment model, 
indicative of homogeneous gas exchange (15). Outcomes using the adult oxyhemoglobin curve as a reference are provided in Table E2 (online data supplement) for comparative purposes.

Shift was increased and $\mathrm{V}_{\mathrm{A}} / \mathrm{Q}$ was decreased in infants with mild, moderate or severe BPD compared to no BPD, and for infants with severe BPD compared to mild BPD. Shift was also increased in moderate compared to mild BPD. The difference in shift and $\mathrm{V}_{\mathrm{A}} / \mathrm{Q}$ between infants with moderate and severe BPD was not statistically significant.

To understand the basis for the overlap in $95 \%$ confidence intervals between moderate and severe BPD, we characterised the severe BPD group ( $n=33$ ) according to oxygen requirement alone: 3 infants had received less than 28 d supplemental oxygen and were not receiving supplemental oxygen at $36 \mathrm{w}$ PMA; 3 had received at least $28 \mathrm{~d}$ supplemental oxygen but were not receiving supplemental oxygen at $36 \mathrm{w}$ PMA; 11 received at least $28 \mathrm{~d}$ supplemental oxygen but were requiring less than $30 \%$ oxygen at $36 \mathrm{w}$ PMA; with the remaining 16 infants all requiring at least $30 \%$ oxygen at $36 \mathrm{w}$ PMA. Severe BPD infants not requiring supplemental oxygen at $36 \mathrm{w}$ PMA had significantly lower shift and higher $\mathrm{V}_{\mathrm{A}} / \mathrm{Q}$ values than the severe BPD infants requiring oxygen (Table E3, online data supplement). Infants classified as having severe BPD by the NIH criteria who were not receiving oxygen at $36 \mathrm{w}$ PMA had shift and $\mathrm{V}_{\mathrm{A}} / \mathrm{Q}$ values that were not statistically different to infants with no BPD ( $p=0.175$ and $p=0.389$ respectively), suggesting absence of significant parenchymal pathology despite their BPD classification.

Shunt was increased in infants with severe BPD compared to infants with no BPD or mild BPD, and in infants with moderate BPD compared to infants with no BPD. There was no difference in shunt between infants with no BPD or mild BPD, or between moderate and severe BPD. Shunt in infants with severe BPD not requiring oxygen at $36 \mathrm{w}$ PMA (Table E3, online data supplement) was not significantly different from shunt in infants with no BPD or mild BPD $(p=1.0$ and $p=1.0)$. There was no difference in shunt between infants classified as severe BPD requiring or not requiring supplemental oxygen $(\mathrm{p}=$ $0.153)$. 
Shift was the outcome variable with the greatest area under the curve as an indicator of the presence of any BPD or moderate-severe BPD on ROC analysis (Table 3). Restriction of the ROC analysis to define a threshold shift value for moderate to severe BPD according to requirement for supplemental oxygen at 36 w PMA alone resulted in a small increase in the threshold shift level, with increased sensitivity and increased specificity. Specificity of the ROC was lower for the threshold shift value discriminating between infants with no BPD and any BPD.

\section{Univariate Analyses for Potential Explanatory Variables and Principle Components Analyses}

Univariate analyses of antenatal factors, perinatal characteristics, markers of disease severity, nutrition, growth and maturity at test relative to shift, $\mathrm{V}_{\mathrm{A}} / \mathrm{Q}$ and shunt are shown in Table E4 (online data supplement). A graph of shift versus both gestation and duration of ventilation relative to oxygen requirements at $36 \mathrm{w}$ PMA is shown in Figure E1 (online data supplement). Principal components analysis identified multi-collinearity between these variables and grouped potential influential perinatal factors into four key factors defining postnatal nutrition (average daily protein, fluid and caloric intake over the first month of life), postnatal illness severity (duration of mechanical ventilation, postnatal steroids and airleak), maturation at birth (gestation), and health status at test (non-invasive ventilation and postmenstrual age at test) as shown in Table E5 (online data supplement).

\section{Multiple linear Regression}

Shift and $\mathrm{V}_{\mathrm{A}} / \mathrm{Q}$ were principally defined by gestational age and duration of mechanical ventilation (Table 4): together these explanatory variable accounted for $34.4 \%$ of the variability in shift and $23.7 \%$ of the variability in $\mathrm{V}_{\mathrm{A}} / \mathrm{Q}$. Shunt was principally defined by duration of mechanical ventilation, and to a lesser extent by gestation, which together accounted for $19.2 \%$ of the total variability in measurement of shunt (Table 4). 


\section{Discussion}

We derived three indices of gas exchange (right shift of the $\mathrm{SpO}_{2} \mathrm{vs}_{\mathrm{I}} \mathrm{O}_{2}$ curve, reduced $\mathrm{V}_{\mathrm{A}} / \mathrm{Q}$ and shunt) using paired measurements of $\mathrm{SpO}_{2}$ and $\mathrm{P}_{\mathrm{I}} \mathrm{O}_{2}$ obtained at 36 weeks' postmenstrual age in 219 preterm infants less than 32 weeks' gestation. Key observations include the utility of shift to provide a continuous measure of impaired gas exchange, and the identification of shunt as a marker of impaired gas exchange in infants with moderate to severe BPD. Importantly, we show that infants with mild BPD using the NIH classification of BPD (oxygen for at least 28 days but not at $36 \mathrm{w}$ postmenstrual age)(2) have a significant impairment in gas exchange despite being classified as "no BPD” by the Walsh test (4).

Whereas summary measures of shift, ventilation-perfusion ratio and shunt differed between BPD severity levels, there was variance within each group and considerable overlap between the NIH classification levels. This overlaps suggests that the NIH severity classification incompletely identifies or differentiates functional pulmonary pathophysiology after preterm birth. The most important explanatory variables accounting for variance in shift, $\mathrm{V}_{\mathrm{A}} / \mathrm{Q}$ and shunt were maturity at birth (gestation) and disease severity, exemplified by duration of mechanical ventilation after adjusting for gestational age.

Strengths of our study include the large cohort size and the use of sub-atmospheric oxygen concentrations to obtain outcome measures across the no BPD to severe BPD spectrum (2). These features distinguish this study from previous smaller ( $\leq 32$ infants), and underpowered investigations $(9,11,12)$, and facilitated identification of physiological thresholds for shift, $\mathrm{V}_{\mathrm{A}} / \mathrm{Q}$ and shunt that align with the NIH classification of BPD severity (2).

We identified distinct differences between NIH BPD severity levels for shift except in the change from moderate to severe BPD. The significant changes in shift and $\mathrm{V}_{\mathrm{A}} / \mathrm{Q}$ in infants with mild BPD compared to infants with no BPD is an important observation highlighting the failings of the Walsh physiological classification of BPD (4). Non-separation of the summary measure of shift for moderate and severe BPD was due in part to the inclusion of infants classified as severe BPD with requirement for mechanical 
respiratory support but no, minimal, or moderate impairment of gas exchange, as illustrated in Figure E1. We did not include a measure of airway function or control of breathing in our assessment. However, the need for ongoing positive pressure in this subset of infants may have an alternative physiological basis than parenchymal lung disease. The pathophysiological basis of respiratory support requirements is an important consideration for future development of a BPD classification to inform ongoing clinical management and outcome prediction.

Recruitment was biased to target a higher proportion of more immature infants than observed in a geographic cohort of preterm births before 32 weeks. However, the even spread of gestational age and disease severity across the cohort improved study power to identify the primary explanatory factors defining the magnitude of our outcome variables.

The studies were well tolerated by all infants. Hypoxic gas mixtures are used routinely pre-flight for assessment of need for supplemental oxygen during air travel, including our preterm infant population $(17,18)$. Stepwise reduction of $\mathrm{P}_{\mathrm{I}} \mathrm{O}_{2}$ commencing the test with a $\mathrm{SpO}_{2}$ of at least $94 \%$, ensured sufficient

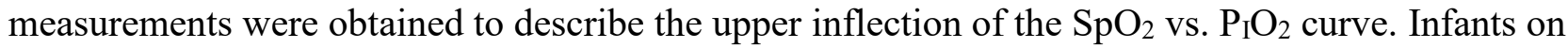
pressure support and a $\mathrm{P}_{\mathrm{I}} \mathrm{O}_{2}>25 \%$ remained on pressure support during the test, to avoid precipitating clinical instability. Maintenance of pressure support in the face of oxygen requirement ensured we captured the gas exchange capacity of the infant without confounding by small airway collapse. Whereas the theoretical impact of commonly used continuous positive airway pressures $\left(5-8 \mathrm{cmH}_{2} \mathrm{O}\right)$ on pressure of inspired oxygen is negligible, the effect of such positive pressure on shift, $\mathrm{V}_{\mathrm{A}} / \mathrm{Q}$ and shunt needs formal evaluation.

The algorithm used to calculate shift, $\mathrm{V}_{\mathrm{A}} / \mathrm{Q}$ and shunt adjusts for current hemoglobin level. These outcome measures were derived using a reference curve based on fetal rather than adult hemoglobin. The fetal curve lies to the left of the adult curve and accounts for the differences between reported values of shift and $\mathrm{V}_{\mathrm{A}} / \mathrm{Q}$ in our population and those reported previously (9). Our approach is justified as the neonatal curve produced better fit to our data and the level of $\mathrm{HbF}$ is related mostly to postmenstrual age 
rather than gestation and the number of previous blood transfusions received $(19,20)$. Compared to the cohort described by Jones et al, all of our data was best fitted to a two-compartment model, indicating homogeneous lung disease across the whole cohort, independent of disease severity. Non requirement of three-compartment modelling in our study may suggest a different population group (21), or may indicate stenting of the airways and reduction of airway obstruction resulting from the use of CPAP or humidified high flow in infants with severe BPD.

Our finding that gestation is the principal independent determinant of shift and $\mathrm{V}_{\mathrm{A}} / \mathrm{Q}$ and also influences shunt confirms current understanding of the negative impact of premature transition to ex utero life on growth and development of the lung. These determinants of shift and $\mathrm{V}_{\mathrm{A}} / \mathrm{Q}$ differ from those reported by Dassios et al (12). However, their smaller study $(n=24)$ was undertaken across a wider range of postmenstrual age (29-36 w), did not consider collinearity between potential influential factors (e.g. gestation and birth weight; postmenstrual age and study weight), and did not include regression analysis to identify independent associations. Illness severity defined by the duration of invasive ventilation not accounted for by gestation was also an important independent contributor to impaired gas exchange. Taken together, we conclude that treatments that reduce illness severity and decrease postnatal comorbidity may achieve significant improvements in pulmonary outcomes.

Although $\mathrm{V}_{\mathrm{A}} / \mathrm{Q}$ is derived from shift, the latter had higher sensitivity and specificity for threshold values than either $\mathrm{V}_{\mathrm{A}} / \mathrm{Q}$ or shunt. Accordingly, shift may provide the best diagnostic index for assessing disease severity as a clinical benchmarking tool or as a sensitive outcome determinant for clinical trials.

Importantly, shift may be determined from single paired measurements of $\mathrm{SpO}_{2}$ and $\mathrm{P}_{\mathrm{I}} \mathrm{O}_{2}$ without the need for an extended oxygen reduction test as undertaken in this study. Hence, shift of the oxyhemoglobin dissociation curve offers the ease of a simple, rapid and quantitative bedside assessment of impaired gas exchange that is easily adjusted for altitude (9).

Our study has several limitations. Our endpoint selection of 36 w PMA precludes comparison of preterm outcomes against those obtained in a healthy term cohort. Previously published outcomes for shift, $\mathrm{V}_{\mathrm{A}} / \mathrm{Q}$ 
and shunt for term born infants at a median 3 days postnatal age indicate lower shift, higher $\mathrm{V}_{\mathrm{A}} / \mathrm{Q}$ and similarly low values of shunt relative to the preterm infants without BPD in our study.(22) Although measurements in these term infants were analysed using a reference curve accounting for adult rather than fetal hemoglobin, they may also indicate potential for improvement in gas exchange with more advanced lung development and/or maturation.

Secondly, tests were performed at a slightly lower postmenstrual age in clinically stable infants compared to more immature and sicker babies due to early discharge or inter-hospital transfers. This spread of postmenstrual age may have reduced differences between different disease severity levels. However, post-menstrual age had a non-significant contribution to the regression model and hence the effect of this bias is likely minimal within the current study.

\section{Conclusions}

Shift of the $\mathrm{SpO}_{2}$ vs $\mathrm{P}_{\mathrm{I}} \mathrm{O}_{2}$ curve, $\mathrm{V}_{\mathrm{A}} / \mathrm{Q}$ and shunt provide a simple and safe continuous physiological outcome measure for quantifying the full range of severity of lung disease in very and extremely preterm infants at 36 weeks' postmenstrual age, independent of altitude and local oxygen prescribing protocols. The presence or absence of these functional impairments are described poorly by the current BPD classifications, which perplexingly define BPD severity from non-standardised, clinician prescribed treatment using arbitrary thresholds. Even preterm infants with no BPD have mild impairment of gas exchange at 36 weeks' postmenstrual age. Infants with mild BPD have worse gas exchange than preterm infants with no BPD, despite classification as no BPD according to the Walsh physiological classification of BPD (4). Further, evidence of increased shunt in infants with moderate to severe BPD may signal a need for incorporating cardiological follow-up into planning for healthcare after initial hospital discharge.

Future studies should evaluate the repeatability and reproducibility of these measures, evaluate the use of this technique to quantify improvement or deterioration in gas exchange over time, identify its utility for clinical benchmarking, prediction of poor respiratory outcomes and as a sensitive outcome to assess the effect of clinical interventions on lung development. Validation of right shift of the $\mathrm{SpO}_{2} / \mathrm{P}_{\mathrm{I}} \mathrm{O}_{2}$ curve from 
a single paired measurement of $\mathrm{SpO}_{2}$ and $\mathrm{P}_{\mathrm{I}} \mathrm{O}_{2}$ will facilitate global utilisation of this objective assessment for these purposes.

\section{Acknowledgements}

The authors would like to acknowledge the research nurses Natasha Mackay-Coghill, and Amanda Woods, Honours students Zeena Al-Obaidi and Jane Choi, and all the included infants, and their parents. We would like to acknowledge Dr GG Lockwood for kindly providing the computer program used for analysis of shift, $\mathrm{V}_{\mathrm{A}} / \mathrm{Q}$ and shunt. We also acknowledge the important preliminary studies undertaken by Dr Alex Wood in 2011, the data from which contributed to obtaining the funding for this grant and development of the measurement protocol. Ms Nash Kahn is thanked for her assistance with database design, development and management. 


\section{References}

1. Bancalari E, Claure N, Sosenko IR. Bronchopulmonary dysplasia: changes in pathogenesis, epidemiology and definition. Semin Neonatol 2003; 8: 63-71.

2. Jobe AH, Bancalari E. Bronchopulmonary dysplasia. Am J Respir Crit Care Med 2001; 163: 17231729.

3. Walsh MC, Wilson-Costello D, Zadell A, Newman N, Fanaroff A. Safety, reliability, and validity of a physiologic definition of bronchopulmonary dysplasia. J Perinatol 2003; 23: 451-456.

4. Walsh MC, Yao Q, Gettner P, Hale E, Collins M, Hensman A, Everette R, Peters N, Miller N, Muran G, Auten K, Newman N, Rowan G, Grisby C, Arnell K, Miller L, Ball B, McDavid G, National Institute of Child H, Human Development Neonatal Research N. Impact of a physiologic definition on bronchopulmonary dysplasia rates. Pediatr 2004; 114: 1305-1311.

5. Higgins RD, Jobe AH, Koso-Thomas M, Bancalari E, Viscardi RM, Hartert TV, Ryan RM, Kallapur SG, Steinhorn RH, Konduri GG, Davis SD, Thebaud B, Clyman RI, Collaco JM, Martin CR, Woods JC, Finer NN, Raju TNK. Bronchopulmonary Dysplasia: Executive Summary of a Workshop. J Pediatr 2018; 197: 300-308.

6. Roe PG, Jones JG. Analysis of factors which affect the relationship between inspired oxygen partial pressure and arterial oxygen saturation. Br J Anaesth 1993; 71: 488-494.

7. Sapsford DJ, Jones JG. The PIO2 vs. SpO2 diagram: a non-invasive measure of pulmonary oxygen exchange. Eur J Anaesthesiol 1995; 12: 375-386.

8. Smith HL, Jones JG. Non-invasive assessment of shunt and ventilation/perfusion ratio in neonates with pulmonary failure. Arch Dis Child Fetal Neonatal Ed 2001; 85: F127-132.

9. Quine D, Wong CM, Boyle EM, Jones JG, Stenson BJ. Non-invasive measurement of reduced ventilation:perfusion ratio and shunt in infants with bronchopulmonary dysplasia: a physiological definition of the disease. Arch Dis Child Fetal Neonatal Ed 2006; 91: F409-414.

10. Rowe L, Jones JG, Quine D, Bhushan SS, Stenson BJ. A simplified method for deriving shunt and reduced VA/Q in infants. Arch Dis Child Fetal Neonatal Ed 2010; 95: F47-52.

11. Bamat N, Ghavam S, Liu Y, DeMauro SB, Jensen EA, Roberts R, Yoder BA, Kirpalani H. Reliability of a Noninvasive Measure of V./Q. Mismatch for Bronchopulmonary Dysplasia. Ann Am Thorac Soc 2015; 12: 727-733.

12. Dassios T, Curley A, Morley C, Ross-Russell R. Using Measurements of Shunt and Ventilation-toPerfusion Ratio to Quantify the Severity of Bronchopulmonary Dysplasia. Neonatology 2015; 107: 283-288.

13. Svedenkrans J, Wood AJT, Pillow JJ. Predictors of right shift and ventilation/perfusion in very preterm infants. J Paediatr Child Health 2015; 51: 20.

14. Svedenkrans J, Stoecklin B, Jones JG, Gill AW, Doherty D, Pillow JJ. Physiological bais of the NICHD BPD Classification: A prospective observational study in very preterm infants. J Pediatr Neonat Individual Med 2017; 6: e060236. 
15. Lockwood GG, Fung NL, Jones JG. Evaluation of a computer program for non-invasive determination of pulmonary shunt and ventilation-perfusion mismatch. J Clin Monit Comput 2014; 28: 581-590.

16. Harris PA, Taylor T, Thielke R, Payne J, Gonzalez N, Conde JG. Research electronic data capture (REDCap) - A metadata-driven methodology and workflow process for providing translational research informatics support. J Biomed Inform 2009; 42: 377-381.

17. Resnick SM, Hall GL, Simmer KN, Stick SM, Sharp MJ. The hypoxia challenge test does not accurately predict hypoxia in flight in ex-preterm neonates. Chest 2008; 133: 1161-1166.

18. Hall GL, Verheggen M, Stick SM. Assessing fitness to fly in young infants and children. Thorax 2007; 62: 278-279.

19. Berglund SK, Lindberg J, Westrup B, Domellof M. Effects of iron supplements and perinatal factors on fetal hemoglobin disappearance in LBW infants. Pediatr Res 2014; 76: 477-482.

20. Bard H, Prosmanne J. Postnatal fetal and adult hemoglobin synthesis is preterm infants whose birth weight was less than 1,000 grams. J Clin Invest 1982; 70: 50-52.

21. Jones JG, Lockwood GG, Fung N, Lasenby J, Ross-Russell RI, Quine D, Stenson BJ. Influence of pulmonary factors on pulse oximeter saturation in preterm infants. Arch Dis Child Fetal Neonatal Ed 2016; 101: F319-322.

22. Dassios T, Ali K, Rossor T, Greenough A. Ventilation/perfusion ratio and right to left shunt in healthy newborn infants. J Clin Monit Comput 2017; 31: 1229-1234. 


\section{Figure Legends}

Figure 1. Oxygen Saturation vs. Oxygen Pressure. The figure shows a plot of oxygen saturation vs. oxygen pressure in a preterm infant (open squares, solid line) compared with a predicted normal curve (long dashed line) in a healthy infant alongside the fetal oxygen dissociation curve (ODC, short dashed line). In this example the preterm infant's curve gave a right shift of $13.5 \mathrm{kPa}$ from the position of the ODC at the steepest part of the curve below $90 \% \mathrm{SpO}_{2}$, a $\mathrm{V}_{\mathrm{A}} / \mathrm{Q}$ of 0.55 , and a shunt of $19 \%$. Dotted reference lines for $90 \% \mathrm{SpO}_{2}$ and $21 \mathrm{kPa}$ oxygen are shown.

Figure 2. Flowchart describing the inclusion pathway of the studied infants. Of 1088 infants born during the study period, 43 had major congenital malformations, leaving 1045 eligible infants. Parents of 508 infants were not approached, and parental consent was not given for an additional 248 infants, resulting in 289 infants enrolled. 219 of the 291 enrolled infants had a completed test. Reasons for noncompletion of the test included early transfer to another hospital $(n=59)$, deceased or too sick to be tested $(n=6)$, withdrawal of consent prior to study $(n=1)$, and other $(n=4)$.

Figure 3. Shift, VA/Q and shunt for included infants relative to NIH BPD classification. Mean values and $95 \%$ confidence intervals for $A$ ) shift, B) $V_{A} / Q$, and C) shunt for infants with no BPD, mild BPD, moderate BPD and severe BPD. Accompanying dot plot shows the spread of individual measurements. 


\section{Tables}

Table 1. Comparison of patient demographics for eligible and recruited infant subpopulations

\begin{tabular}{|c|c|c|c|c|c|c|c|}
\hline & \multirow[b]{2}{*}{$\mid \begin{array}{c}\text { all eligible infants } \\
n=1045\end{array}$} & \multirow[b]{2}{*}{$\begin{array}{l}\text { not enrolled } \\
\qquad \mathrm{n}=756\end{array}$} & \multirow[b]{2}{*}{$\begin{array}{l}\text { enrolled } \\
n=289\end{array}$} & \multicolumn{2}{|c|}{ Included in the PIFCO cohort } & \multicolumn{2}{|c|}{ p value $(95 \% \mathrm{CI})$} \\
\hline & & & & $\begin{array}{l}\text { tested } \\
n=219\end{array}$ & $\begin{array}{l}\text { not tested } \\
n=70\end{array}$ & $\begin{array}{c}\text { not enrolled vs } \\
\text { enrolled }\end{array}$ & $\begin{array}{l}\text { tested vs } \\
\text { not tested }\end{array}$ \\
\hline male $(\mathrm{n}, \%$ male $)$ & $600(57 \cdot 4)$ & $415(54.9)$ & $185(64 \cdot 0)$ & $138(63 \cdot 0)$ & $47(67 \cdot 1)$ & $0 \cdot 008$ & $0 \cdot 531$ \\
\hline GA (median, IQR) & $29 \cdot 3(27 \cdot 1,31 \cdot 0)$ & $30 \cdot 0(27 \cdot 0,31 \cdot 0)$ & $28 \cdot 0(26 \cdot 0,30 \cdot 0)$ & $28.0(26 \cdot 0,9 \cdot 0)$ & $29 \cdot 0(27 \cdot 0,31 \cdot 0)$ & $<0 \cdot 001(1 \cdot 0,2 \cdot 0)^{*}$ & $0 \cdot 001(0 \cdot 0,2 \cdot 0)^{*}$ \\
\hline BW (mean, SD) & $1217(401)$ & $1260(415)$ & $1104(336)$ & $1070(318)$ & $1209(369)$ & $<0 \cdot 001(103 \cdot 2,210 \cdot 4)^{\dagger}$ & $0 \cdot 002(49 \cdot 3,237 \cdot 0)^{\dagger}$ \\
\hline BW z-score (mean, SD) & $0.01(0 \cdot 89)$ & $0 \cdot 00(0 \cdot 90)$ & $0 \cdot 01(0 \cdot 86)$ & $0 \cdot 02(0 \cdot 87)$ & $-0.01(0 \cdot 83)$ & $0 \cdot 877(-0 \cdot 130,0 \cdot 111)^{\dagger}$ & $0 \cdot 799(-0 \cdot 260,0 \cdot 198)^{\dagger}$ \\
\hline Any choriamnionitis (n, \%) & $153(14 \cdot 6)$ & $109(14 \cdot 4)$ & $44(15 \cdot 2)$ & $37(16 \cdot 9)$ & $7(10 \cdot 0)$ & $0 \cdot 741$ & $0 \cdot 162$ \\
\hline Any antenatal steroid (n,\%) & $1002(95 \cdot 9)$ & $721(95 \cdot 4)$ & $281(97 \cdot 2)$ & $212(96 \cdot 8)$ & $69(98 \cdot 6)$ & $0 \cdot 175$ & $0 \cdot 433$ \\
\hline Any postnatal steroids (n, \%) & $49(4 \cdot 7)$ & $33(4 \cdot 4)$ & $16(5 \cdot 5)$ & $14(6 \cdot 4)$ & $2(2 \cdot 9)$ & $0 \cdot 423$ & $0 \cdot 260$ \\
\hline MV (d; median, IQR) & $0 \cdot 3(0 \cdot 0 \cdot 18)$ & $0 \cdot 3(0 \cdot 0,1 \cdot 6)$ & $0 \cdot 5(0,3 \cdot 5)$ & $0 \cdot 6(0,4 \cdot 9)$ & $0 \cdot 15(0 \cdot 0,1 \cdot 0)$ & $<0 \cdot 001(-0 \cdot 30,0 \cdot 00)^{*}$ & $0 \cdot 005(-0 \cdot 5,0 \cdot 0)^{*}$ \\
\hline Moderate to severe BPD (n, \%) & $136(13 \cdot 0)$ & $70(9 \cdot 3)$ & $66(22 \cdot 8)$ & $57(26 \cdot 0)$ & $9(12 \cdot 9)$ & $<0 \cdot 001$ & $0 \cdot 022$ \\
\hline
\end{tabular}

GA - Gestational age, BW - Birth weight, BPD - Bronchopulmonary dysplasia; MV - mechanical ventilation; ${ }^{*}$ Mann-Whitney U Test, ${ }^{\dagger} \mathrm{t}$-test. 


\begin{tabular}{|c|c|c|c|c|c|}
\hline & all tested infants & no BPD & mild BPD & moderate BPD & severe BPD \\
\hline $\mathrm{N}$ & 219 & 133 & 29 & 24 & 33 \\
\hline \multicolumn{6}{|l|}{ MATERNAL FACTORS } \\
\hline Any maternal betamethasone (n, \%) & $213(96 \cdot 8)$ & $128(96 \cdot 2)$ & $28(96 \cdot 6)$ & $24(100)$ & $33(100)$ \\
\hline Rupture of membranes $>72 \mathrm{~h}(\mathrm{n}, \%)$ & $37(16 \cdot 9)$ & $28(21 \cdot 1)$ & $4(13 \cdot 8)$ & $1(4 \cdot 2)$ & $4(12 \cdot 1)$ \\
\hline Fever $>38.0{ }^{\circ} \mathrm{C}$ in labour $(\mathrm{n}, \%)$ & $13(5 \cdot 9)$ & $5(3 \cdot 8)$ & $3(10 \cdot 3)$ & $1(4 \cdot 2)$ & $4(12 \cdot 1)$ \\
\hline Histological choriamnionitis $(\mathrm{n}, \%)$ & $121(55 \cdot 3)$ & $62(46 \cdot 6)$ & $20(69 \cdot 0)$ & $17(70 \cdot 8)$ & $22(66 \cdot 7)$ \\
\hline \multicolumn{6}{|l|}{ BIRTH \& EARLY POSTNATAL TREATMENT } \\
\hline Male (n, \%) & $138(63 \cdot 0)$ & $83(62 \cdot 4)$ & $20(69 \cdot 0)$ & $19(79 \cdot 2)^{*}$ & $16(48 \cdot 5)$ \\
\hline Gestational age (mean, SD) & $27 \cdot 9(26 \cdot 0,29 \cdot 6)$ & $29 \cdot 1(1 \cdot 6)$ & $25.7(1 \cdot 5)^{*}$ & $26 \cdot 1(1 \cdot 9)^{*}$ & $25 \cdot 6(1 \cdot 6)^{*}$ \\
\hline Birth weight (mean, SD) & $1071(318)$ & $1221(277)$ & $908(275)^{*}$ & $825(161)^{*}$ & $788(209)^{*}$ \\
\hline Birth weight z-score (mean, SD) & $0 \cdot 07(0 \cdot 85)$ & $-0 \cdot 03(0 \cdot 79)$ & $0.45(0.71)^{*}$ & $0 \cdot 17(0.98)^{*}$ & $0 \cdot 10(1 \cdot 00)^{*}$ \\
\hline APGAR at 5 min (median, IQR) & $8(7,9)$ & $8(7,9)$ & $7(7,9)$ & $8(7,9)$ & $7(7,9)$ \\
\hline Multiple birth (n, \%) & $52(23 \cdot 7)$ & $38(28 \cdot 6)$ & $8(27 \cdot 6)$ & $3(12 \cdot 5)$ & $3(9 \cdot 1)$ \\
\hline Intubated in $1 \mathrm{st} 48 \mathrm{~h}(\mathrm{n}, \%)$ & $161(73 \cdot 5)$ & $77(56 \cdot 9)$ & $29(91 \cdot 9)^{*}$ & $24(100)^{*}$ & $31(93 \cdot 5)^{*}$ \\
\hline Surfactant $(n, \%)$ & $159(72 \cdot 6)$ & $75(56 \cdot 4)$ & $29(100)^{*}$ & $24(100)^{*}$ & $31(93 \cdot 9)^{*}$ \\
\hline \multicolumn{6}{|l|}{ MATURITY AT TEST } \\
\hline Postnatal age (d; mean, SD) & $53 \cdot 1(18 \cdot 8)$ & $41 \cdot 6(12 \cdot 4)$ & $68 \cdot 9(11 \cdot 8)^{*}$ & $69 \cdot 8(12 \cdot 2)^{*}$ & $73 \cdot 6(11 \cdot 7)^{*}$ \\
\hline PMA at test (w; median, IQR) & $35 \cdot 4(34 \cdot 7,39 \cdot 3)$ & $35 \cdot 0(34 \cdot 6,35 \cdot 6)$ & $35 \cdot 6(35 \cdot 1,36 \cdot 3)^{*}$ & $35 \cdot 8(35 \cdot 4,36 \cdot 1)^{*}$ & $36 \cdot 1(35 \cdot 5,36 \cdot 7)^{*}$ \\
\hline \multicolumn{6}{|l|}{ POSTNATAL GROWTH AND NUTRITION } \\
\hline 36 w PMA weight (g; mean, SD) & $2346(433)$ & $2195(373)$ & $2620(383)^{*}$ & $2570(372)^{*}$ & $2547(479)^{*}$ \\
\hline 36 w PMA weight $z$-score (mean, SD) & $-0 \cdot 68(0 \cdot 90)$ & $-0 \cdot 79(0 \cdot 88)$ & $-0 \cdot 23(0 \cdot 87)^{*}$ & $-0.47(0 \cdot 76)^{*}$ & $-0.75(0.97)^{*}$ \\
\hline 36 w PMA length (cm; mean, SD) & $44 \cdot 2(2 \cdot 16)$ & $43 \cdot 9(2 \cdot 08)$ & $44 \cdot 8(2 \cdot 08)$ & $44 \cdot 6(1 \cdot 67)$ & $44 \cdot 5(2 \cdot 80)$ \\
\hline 36 w PMA length z-score (mean, SD) & $-0 \cdot 99(0 \cdot 87)$ & $-0 \cdot 87(0 \cdot 86)$ & $-0.97(0 \cdot 76)^{*}$ & $-1 \cdot 15(0 \cdot 71)^{*}$ & $-1 \cdot 38(0 \cdot 86)^{*}$ \\
\hline Weight z-score change birth to $36 \mathrm{w}$ PMA (mean, SD) & $-0 \cdot 75(0 \cdot 71)$ & $-0 \cdot 76(0 \cdot 59)$ & $-0 \cdot 68(0 \cdot 84)$ & $-0 \cdot 63(0 \cdot 88)$ & $-0 \cdot 87(0 \cdot 86)$ \\
\hline Fluid intake $1^{\text {st }} 28 \mathrm{~d}(\mathrm{~mL} / \mathrm{kg} / \mathrm{d} ;$ mean, SD) & $150(7 \cdot 3)$ & $152(7 \cdot 0)$ & $149(5 \cdot 0)^{*}$ & $147(8 \cdot 4)^{*}$ & $147(7 \cdot 5)^{*}$ \\
\hline Caloric intake $1^{\text {st }} 28 \mathrm{~d}(\mathrm{kcal} / \mathrm{kg} / \mathrm{d}$; mean, SD) & $110(13 \cdot 3)$ & $116(10 \cdot 0)$ & $104(12 \cdot 6)^{*}$ & $98 \cdot 3(11 \cdot 0)^{*}$ & $97 \cdot 7(11 \cdot 0)^{*}$ \\
\hline Protein intake $1^{\text {st }} 28 \mathrm{~d}(\mathrm{~g} / \mathrm{kg} \mathrm{BW} / \mathrm{d}$; mean, SD) & $3 \cdot 4(0 \cdot 3)$ & $3 \cdot 5(0 \cdot 3)$ & $3 \cdot 3(0 \cdot 4)^{*}$ & $3 \cdot 2(0 \cdot 3)^{*}$ & $3 \cdot 2(0 \cdot 3)^{*}$ \\
\hline $\mathrm{Hb}($ median, IQR) & $103(92,115)$ & $100(90,114)$ & $101(92,115)$ & $108(98,119)$ & $111(101,126)$ \\
\hline \multicolumn{6}{|l|}{ DISEASE SEVERITY } \\
\hline Mechanical ventilation (d; median, IQR) & $0 \cdot 6(0 \cdot 0,4 \cdot 9)$ & $0 \cdot 3(0 \cdot 0,0 \cdot 7)$ & $4 \cdot 3(1 \cdot 0,16 \cdot 9)^{*}$ & $6 \cdot 6(1 \cdot 0,25 \cdot 1)^{*}$ & $32.0(4 \cdot 3,44 \cdot 9)^{*}$ \\
\hline Non-invasive ventilation (d; median, IQR) & $43 \cdot 3(8 \cdot 0,61 \cdot 5)$ & $15 \cdot 2(3 \cdot 0,42 \cdot 2)$ & $64 \cdot 4(51 \cdot 5,73 \cdot 9)^{*}$ & $63 \cdot 0(55 \cdot 8,74 \cdot 2)^{*}$ & $69 \cdot 1(52 \cdot 4,78 \cdot 8)^{*}$ \\
\hline Supplemental oxygen (d; median, IQR) & $5 \cdot 0(0 \cdot 2,56 \cdot 3)$ & $0 \cdot 5(0 \cdot 0,3 \cdot 4)$ & $50 \cdot 0(35 \cdot 0,64 \cdot 7)^{*}$ & $80 \cdot 8(58 \cdot 4,95 \cdot 9)^{*}$ & $106(78 \cdot 4,137)^{*}$ \\
\hline Any postnatal steroids (n, \%) & $14(6 \cdot 4)$ & $0(0 \cdot 0)$ & $0(0 \cdot 0)$ & $1(4 \cdot 2)$ & $13(39 \cdot 4)^{*}$ \\
\hline Any hyaline membrane disease $(\mathrm{n}, \%)$ & $199(90 \cdot 9)$ & $114(85 \cdot 7)$ & $29(100 \cdot 0)$ & $24(100 \cdot 0)$ & $32(97 \cdot 0)$ \\
\hline Any air leak $(n, \%)$ & $14(6 \cdot 4)$ & $4(3 \cdot 0)$ & $1(3 \cdot 4)^{*}$ & $1(4 \cdot 2)^{*}$ & $8(24 \cdot 2)^{*}$ \\
\hline Any pulmonary hemorrhage $(\mathrm{n}, \%)$ & $9(4 \cdot 1)$ & $1(0 \cdot 8)$ & $1(3 \cdot 4)^{*}$ & $5(20 \cdot 8)^{*}$ & $2(6 \cdot 1)^{*}$ \\
\hline Any sepsis $(\mathrm{n}, \%)$ & $33(15 \cdot 1)$ & $6(4 \cdot 5)$ & $6(20 \cdot 7)^{*}$ & $10(41 \cdot 7)^{*}$ & $11(33 \cdot 3)^{*}$ \\
\hline Any intraventricular hemorrhage $(\mathrm{n}, \%)$ & $43(19 \cdot 6)$ & $20(15 \cdot 0)$ & $7(24 \cdot 1)$ & $7(29 \cdot 2)$ & $9(27 \cdot 3)$ \\
\hline Any periventricular leukomalacia (n, \%) & $2(0 \cdot 9)$ & $0(0 \cdot 0)$ & $0(0 \cdot 0)$ & $0(0 \cdot 0)$ & $2(6 \cdot 1)$ \\
\hline Any necrotising enterocolitis (n, \%) & $5(2 \cdot 3)$ & $1(0 \cdot 8)$ & $2(6 \cdot 9)$ & $0(0 \cdot 0)$ & $2(6 \cdot 1)$ \\
\hline
\end{tabular}

BPD - bronchopulmonary dysplasia; Hb - hemoglobin; PMA - postmenstrual age; * significantly different to 'No BPD'. 
Table 3: Thresholds for Shift, $V_{\mathrm{A}} / \mathrm{Q}$ and Shunt for Any BPD and Moderate-Severe BPD

\begin{tabular}{|c|c|c|c|c|c|c|}
\hline Measure & Comparison Group & AUC & $95 \% \mathrm{CI}$ & Threshold & Sensitivity \% & Specificity \% \\
\hline \multicolumn{7}{|c|}{ Shift (kPa) } \\
\hline & Any BPD & $0 \cdot 899$ & $(0 \cdot 858,0 \cdot 940)$ & $11 \cdot 35$ & $78 \cdot 0$ & $79 \cdot 8$ \\
\hline & \multicolumn{6}{|l|}{ Mod-Severe BPD } \\
\hline & All & $0 \cdot 922$ & $(0 \cdot 879,0 \cdot 966)$ & $12 \cdot 15$ & $82 \cdot 5$ & $86 \cdot 4$ \\
\hline & $\mathrm{O}_{2} @ 36$ w PMA & $0 \cdot 951$ & $(0 \cdot 913,0 \cdot 989)$ & $12 \cdot 31$ & $92 \cdot 7$ & $88 \cdot 2$ \\
\hline \multicolumn{7}{|l|}{$\mathbf{V}_{\mathrm{A}} / \mathbf{Q}$} \\
\hline & Any BPD & $0 \cdot 864$ & $(0 \cdot 814,0 \cdot 915)$ & $0 \cdot 55$ & $78 \cdot 8$ & $76 \cdot 9$ \\
\hline & \multicolumn{6}{|l|}{ Mod-Severe BPD } \\
\hline & All & 0.881 & $(0 \cdot 824,0 \cdot 937)$ & $0 \cdot 54$ & $80 \cdot 7$ & $78 \cdot 4$ \\
\hline & $\mathrm{O}_{2} @ 36$ w PMA & $0 \cdot 921$ & $(0 \cdot 875,0 \cdot 966)$ & $0 \cdot 51$ & 82.9 & $87 \cdot 6$ \\
\hline \multicolumn{7}{|c|}{ Shunt (\%) } \\
\hline & Any BPD & $0 \cdot 683$ & $(0 \cdot 606,0 \cdot 761)$ & $4 \cdot 86$ & $58 \cdot 8$ & $72 \cdot 4$ \\
\hline & \multicolumn{6}{|l|}{ Mod-Severe BPD } \\
\hline & All & $0 \cdot 753$ & $(0 \cdot 668,0 \cdot 837)$ & $5 \cdot 25$ & $70 \cdot 8$ & $78 \cdot 8$ \\
\hline & $\mathrm{O}_{2} @ 36$ w PMA & $0 \cdot 789$ & $(0 \cdot 696,0 \cdot 882)$ & $8 \cdot 14$ & $68 \cdot 3$ & $87 \cdot 1$ \\
\hline
\end{tabular}

AUC, area under the receiver operating curve; BPD, bronchopulmonary dysplasia; CI, confidence interval; PMA, postmenstrual age. 
Table 4: Multivariable Analyses

\begin{tabular}{|c|c|c|c|c|c|c|}
\hline Outcome Variable & Explanatory Variables & Adjusted R ${ }^{2}$ & Coefficient (B) & SE & $95 \%$ CI & p value \\
\hline \multirow[t]{3}{*}{ Right shift (kPa) } & Constant & & $32 \cdot 3$ & $2 \cdot 535$ & $27 \cdot 3,37 \cdot 3$ & $<0 \cdot 0001$ \\
\hline & Gestational age (w) & $0 \cdot 192$ & $-0 \cdot 732$ & $0 \cdot 091$ & $-0 \cdot 91,-0 \cdot 55$ & $<0 \cdot 0001$ \\
\hline & Duration of mechanical ventilation (d)* & $0 \cdot 152$ & $0 \cdot 130$ & $0 \cdot 018$ & $0 \cdot 09,0 \cdot 17$ & $<0 \cdot 0001$ \\
\hline \multirow[t]{4}{*}{$\mathbf{V} / \mathbf{Q}$} & Constant & & $-0 \cdot 187$ & $0 \cdot 094$ & $-0 \cdot 407,0 \cdot 032$ & $0 \cdot 094$ \\
\hline & Gestational age $(\mathrm{w})$ & $0 \cdot 162$ & $0 \cdot 021$ & $0 \cdot 003$ & $0 \cdot 013,0 \cdot 028$ & $<0 \cdot 0001$ \\
\hline & Duration of mechanical ventilation $(d)^{*}$ & $0 \cdot 063$ & $-0 \cdot 003$ & $0 \cdot 001$ & $-0 \cdot 004,-0 \cdot 001$ & $<0 \cdot 0001$ \\
\hline & Average daily protein $1^{\text {st }} 28 \mathrm{~d}(\mathrm{~g} / \mathrm{kg})$ & $0 \cdot 012$ & $0 \cdot 057$ & $0 \cdot .027$ & $0 \cdot 003,0 \cdot 110$ & 0.038 \\
\hline \multirow[t]{3}{*}{ Shunt (\%) } & Constant & & 24.5 & $4 \cdot 99$ & $14.7,34.4$ & $<0 \cdot 0001$ \\
\hline & Duration of mechanical ventilation (d)* & $0 \cdot 136$ & $0 \cdot 209$ & $0 \cdot 035$ & $0 \cdot 137,0 \cdot 274$ & $<0 \cdot 0001$ \\
\hline & Gestational age (w) & $0 \cdot 056$ & $-0 \cdot 703$ & $0 \cdot 181$ & $-1 \cdot 057,-0 \cdot 348$ & $0 \cdot 0001$ \\
\hline
\end{tabular}

SE, standard error; CI, confidence interval. *unstandardised residual of regression against gestational age. 


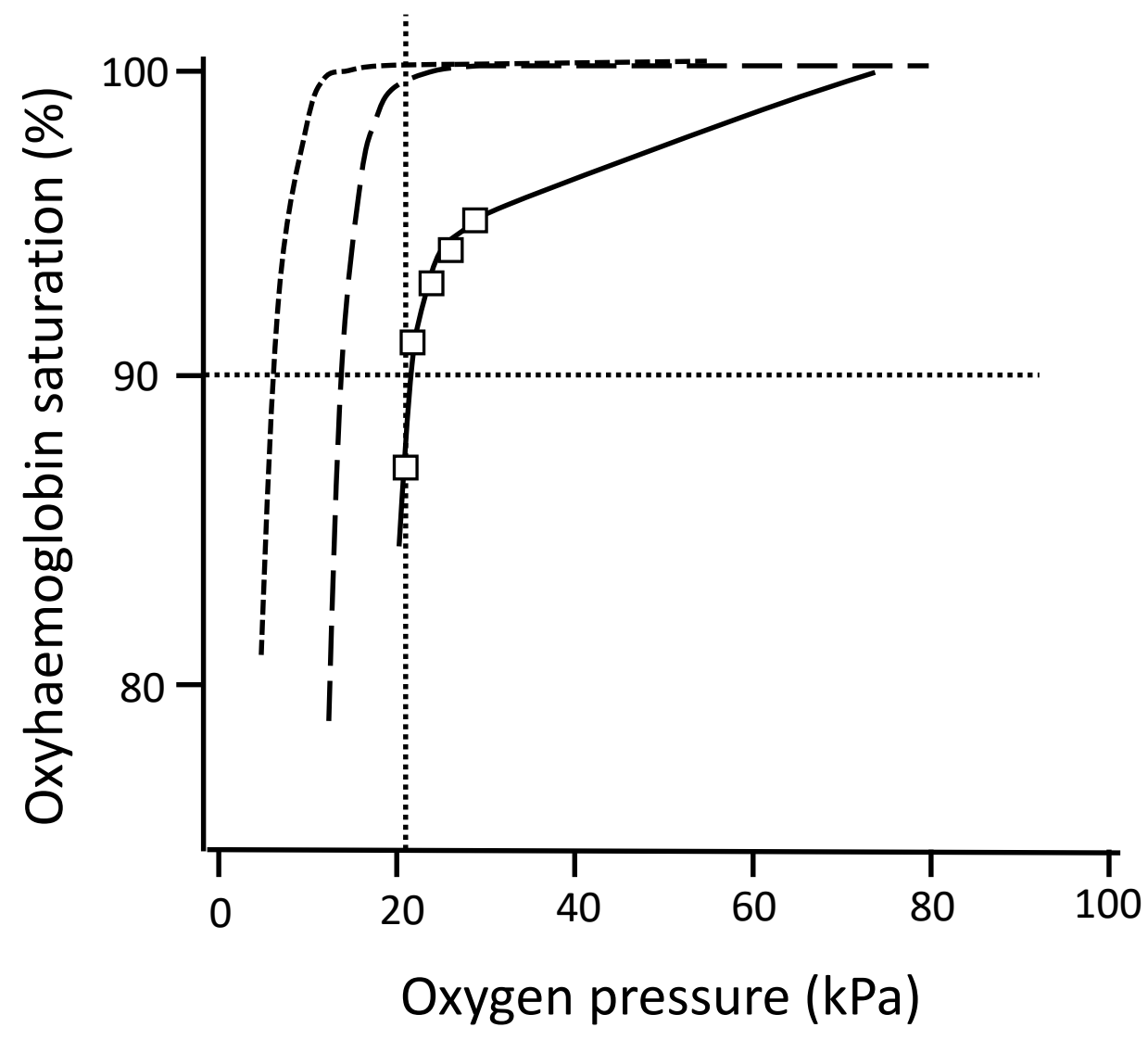


All infants $<32 \mathrm{w}$ GA born at KEMH during the study period, $\mathrm{N}=1088$

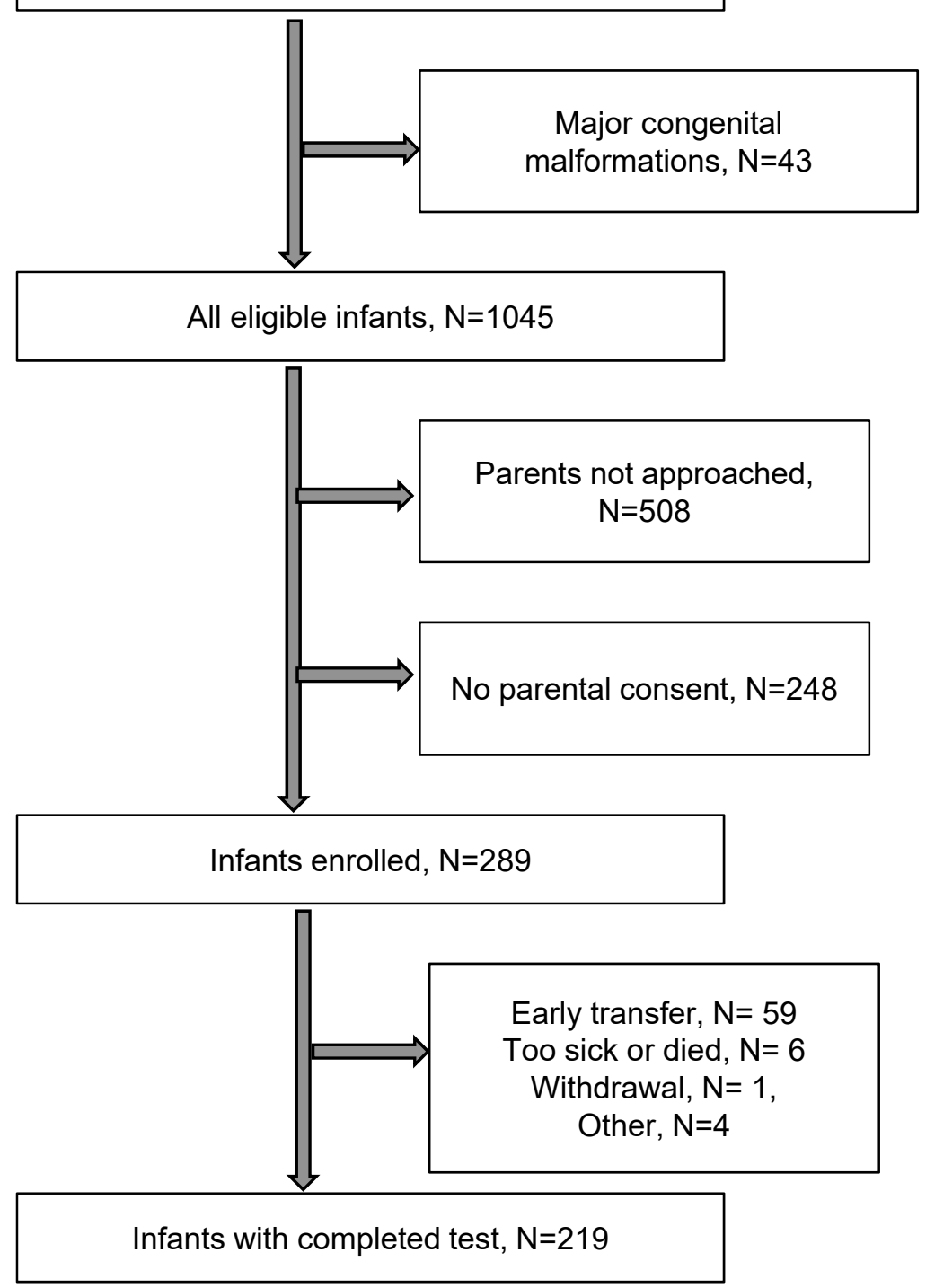



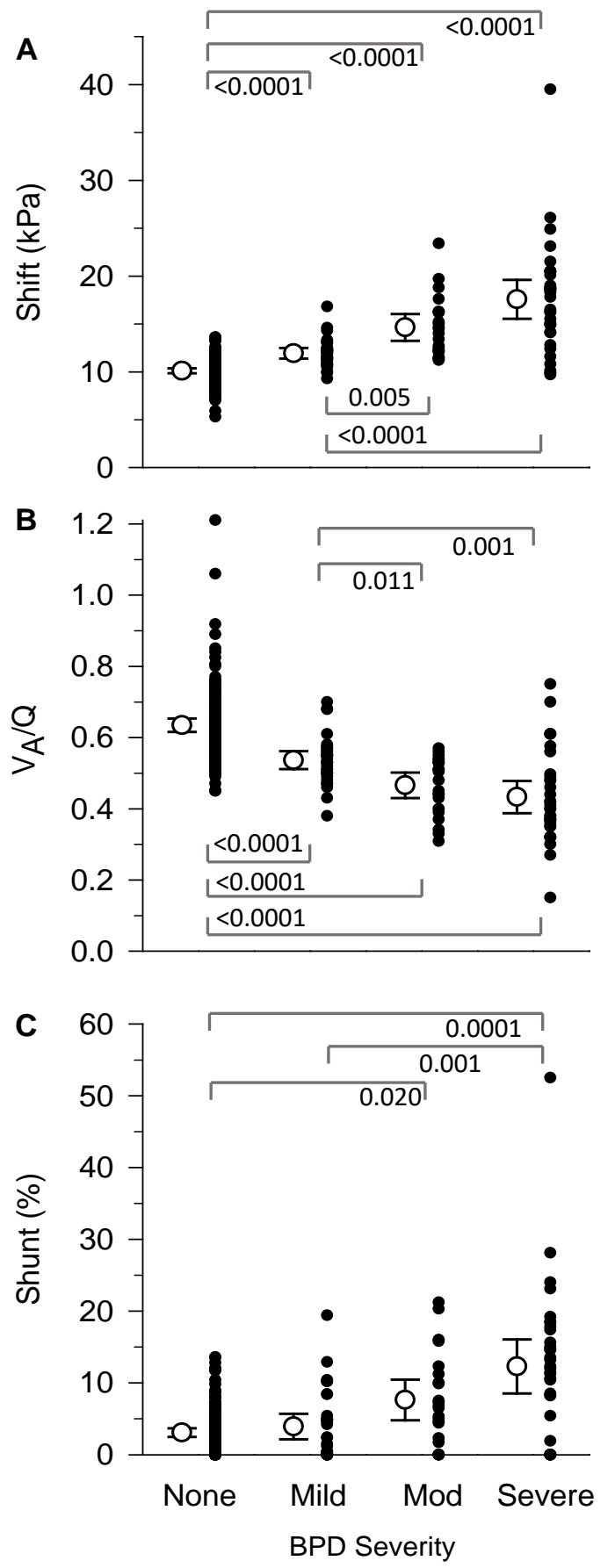


\section{Physiology and predictors of impaired gas exchange in infants with bronchopulmonary dysplasia}

*Jenny Svedenkrans PhD ${ }^{\mathrm{a}, \mathrm{b}, \mathrm{c}}$, *Benjamin Stoecklin $\mathrm{MD}^{\mathrm{a}, \mathrm{d}, \mathrm{e}}$, J. Gareth Jones FRCP ${ }^{\mathrm{f}}$, Dorota A. Doherty $\mathrm{PhD}^{\mathrm{g}}$, J. Jane Pillow ${ }^{\mathrm{a}, \mathrm{d}} \mathrm{PhD}$

\section{Online Data Supplemental Figure}
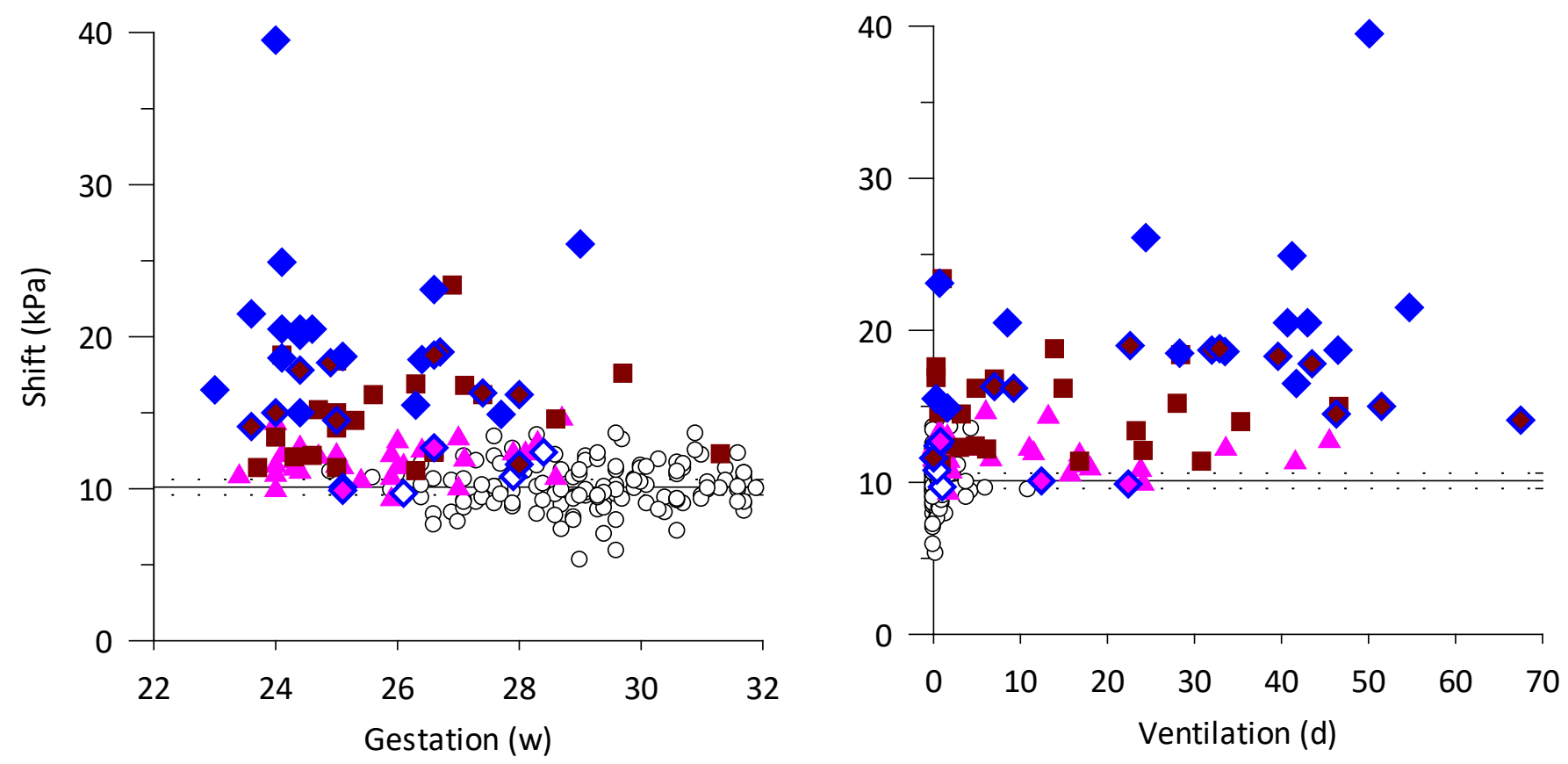

Figure E1. Major determinants of right shift of the $\mathrm{SpO}_{2} / \mathrm{P}_{1} \mathrm{O}_{2}$ curve. Figure shows relation between measured right shift of the $\mathrm{SpO}_{2} / \mathrm{P}_{\mathrm{IO}} \mathrm{O}_{2}$ and gestation (left panel) and duration of invasive ventilation (right panel). Symbols show NIH BPD classification: no BPD (open circle); mild BPD (pink triangle); moderate BPD (brown square) and severe BPD (diamond). The severe BPD symbols (diamond symbols, blue border) are color filled according to whether infants required oxygen for less than $28 \mathrm{~d}$ (white) or according to oxygen requirement at $36 \mathrm{w}$ PMA in those infants requiring supplemental oxygen for at least $28 \mathrm{~d}$ : air (pink), $<30 \%$ (brown) and $\geq 30 \%$ (blue). The mean $(95 \% \mathrm{CI})$ for the no BPD group is shown as a solid (dashed) line for reference. This figure highlights the heterogeneity of oxygen requirements in the severe BPD group, in part accounting for the wide range of shift values in this group. 


\section{Physiology and predictors of impaired gas exchange in infants with bronchopulmonary}

dysplasia

*Jenny Svedenkrans PhD ${ }^{\mathrm{a}, \mathrm{b}, \mathrm{c}}$, *Benjamin Stoecklin $\mathrm{MD}^{\mathrm{a}, \mathrm{d}, \mathrm{e}}$, J. Gareth Jones FRCP ${ }^{\mathrm{f}}$, Dorota A. Doherty $\mathrm{PhD}^{\mathrm{g}}$, J. Jane Pillow ${ }^{\mathrm{a}, \mathrm{d}} \mathrm{PhD}$

\section{Online Data Supplemental Text}

Table E1: Summary values of Shift, $V_{A} / Q$ and Shunt relative to NICHD BPD Classification using the fetal oxyhemoglobin dissociation curve as a reference.

\begin{tabular}{|l|l|l|l|l|}
\hline & no BPD & mild BPD & moderate BPD & severe BPD \\
\hline Shift & $10 \cdot 0(9 \cdot 2,11 \cdot 1)$ & $11 \cdot 9(10 \cdot 9,12 \cdot 4)^{* \mathrm{~b}}$ & $14 \cdot 3(12 \cdot 2,16 \cdot 2)^{* \dagger}$ & $17 \cdot 8(14 \cdot 1,20 \cdot 3)^{* \dagger}$ \\
\hline $\mathrm{V}_{\mathrm{A}} / \mathrm{Q}$ & $0 \cdot 62(0 \cdot 56,0 \cdot 69)$ & $0 \cdot 53(0 \cdot 50,0 \cdot 57)^{*}$ & $0 \cdot 49(0 \cdot 40,0 \cdot 53)^{* \dagger}$ & $0 \cdot 40(0 \cdot 36,0 \cdot 49)^{* \dagger}$ \\
\hline Shunt & $2 \cdot 0(0 \cdot 0,5 \cdot 2)$ & $2 \cdot 4(0 \cdot 0,5 \cdot 4)$ & $6 \cdot 7(2 \cdot 2,11 \cdot 5)^{*}$ & $12 \cdot 0(3 \cdot 7,17 \cdot 6)^{* \dagger}$ \\
\hline
\end{tabular}

$\mathrm{V}_{\mathrm{A}} / \mathrm{Q}$ - ventilation perfusion ratio; Kruskal-Wallis; Values are median (IQR). ${ }^{*} \mathrm{p}<0.05$ compared to no $\mathrm{BPD} ;{ }^{\dagger} \mathrm{p}<0.05$ compared to mild BPD.

Table E2: Summary values of Shift, $V_{A} / Q$ and Shunt relative to NICHD BPD Classification using the adult oxyhemoglobin dissociation curve as a reference.

\begin{tabular}{lllll}
\hline & no BPD & mild BPD & moderate BPD & severe BPD \\
\hline Shift $(\mathrm{kPa})$ & $8 \cdot 4(7 \cdot 7,9 \cdot 6)$ & $10 \cdot 5(9 \cdot 2,11 \cdot 1)^{*}$ & $13 \cdot 0(11 \cdot 2,15 \cdot 0)^{* \dagger \mathrm{c}}$ & $17 \cdot 0(13 \cdot 5,18 \cdot 5)^{* \dagger}$ \\
$\mathrm{V}_{\mathrm{A}} / \mathrm{Q}$ & $0 \cdot 72(0 \cdot 64,0 \cdot 79)$ & $0 \cdot 58(0 \cdot 56,0 \cdot 67)^{*}$ & $0 \cdot 51(0 \cdot 42,0 \cdot 55)^{\mathrm{c}}$ & $0 \cdot 42(0 \cdot 35,0 \cdot 50)^{\mathrm{c}}$ \\
Shunt $(\%)$ & $0 \cdot 0(0 \cdot 0,0 \cdot 0)$ & $0 \cdot 0(0 \cdot 0,0 \cdot 0)$ & $0 \cdot 0(0 \cdot 0,8 \cdot 1)^{* \dagger}$ & $8 \cdot 1(1 \cdot 6,11 \cdot 8)^{* \dagger \ddagger}$ \\
\hline
\end{tabular}

$\mathrm{V}_{\mathrm{A}} / \mathrm{Q}$ - ventilation perfusion ratio; Kruskal-Wallis; Values are median (IQR). Values within a row that do not share the same superscripted letter are significantly different from each other. ${ }^{*} \mathrm{p}<0.05$ compared to no $\mathrm{BPD} ;{ }^{\dagger} \mathrm{p}<0.05$ compared to mild BPD; ${ }^{\ddagger} \mathrm{p}<0.05$ compared to moderate BPD.

Table E3: Summary values of shift, $V_{A} / Q$ and shunt for infants classified as severe BPD according to need for oxygen at 36w PMA.

\begin{tabular}{l|ll|l}
\hline & $\begin{array}{l}\text { no supplemental } \mathbf{O}_{2} \\
(\mathrm{n}=6)\end{array}$ & $\begin{array}{l}\text { supplemental } \mathbf{O}_{2} \\
(\mathrm{n}=25)\end{array}$ & p value \\
\hline Shift $(\mathrm{kPa})$ & $11 \cdot 2(9 \cdot 7,18 \cdot 7)$ & $18 \cdot 8(16 \cdot 6,20 \cdot 9)^{*}$ & $<0 \cdot 001$ \\
$\mathrm{~V}_{\mathrm{A}} / \mathrm{Q}$ & $0 \cdot 59(0 \cdot 54,0 \cdot 65)$ & $0 \cdot 38(0 \cdot 35,0 \cdot 44)^{*}$ & $<0 \cdot 001$ \\
Shunt $(\%)$ & $1.0(0 \cdot 0,17 \cdot 5)$ & $12 \cdot 3(8 \cdot 3,18 \cdot 4)$ & $0 \cdot 153$ \\
\hline
\end{tabular}

$\mathrm{V}_{\mathrm{A}} / \mathrm{Q}$ - ventilation perfusion ratio; Mann-Whitney U; Values are median (IQR). Note that infants not receiving supplemental oxygen but classified as having severe BPD due to need for ongoing invasive or non-invasive respiratory support had lower shift, and higher $\mathrm{V}_{\mathrm{A}} / \mathrm{Q}$ than those infants with a continuing need for oxygen (supplementary Table 1). ${ }^{*}$ compared to infants classified as severe BPD but not requiring supplemental $\mathrm{O}_{2}$ at $36 \mathrm{w}$ PMA. 
Table E4: Pearson correlations ${ }^{\circledR}$ of shift, $V_{\mathrm{A}} / \mathrm{Q}$ and shunt with potential explanatory factors

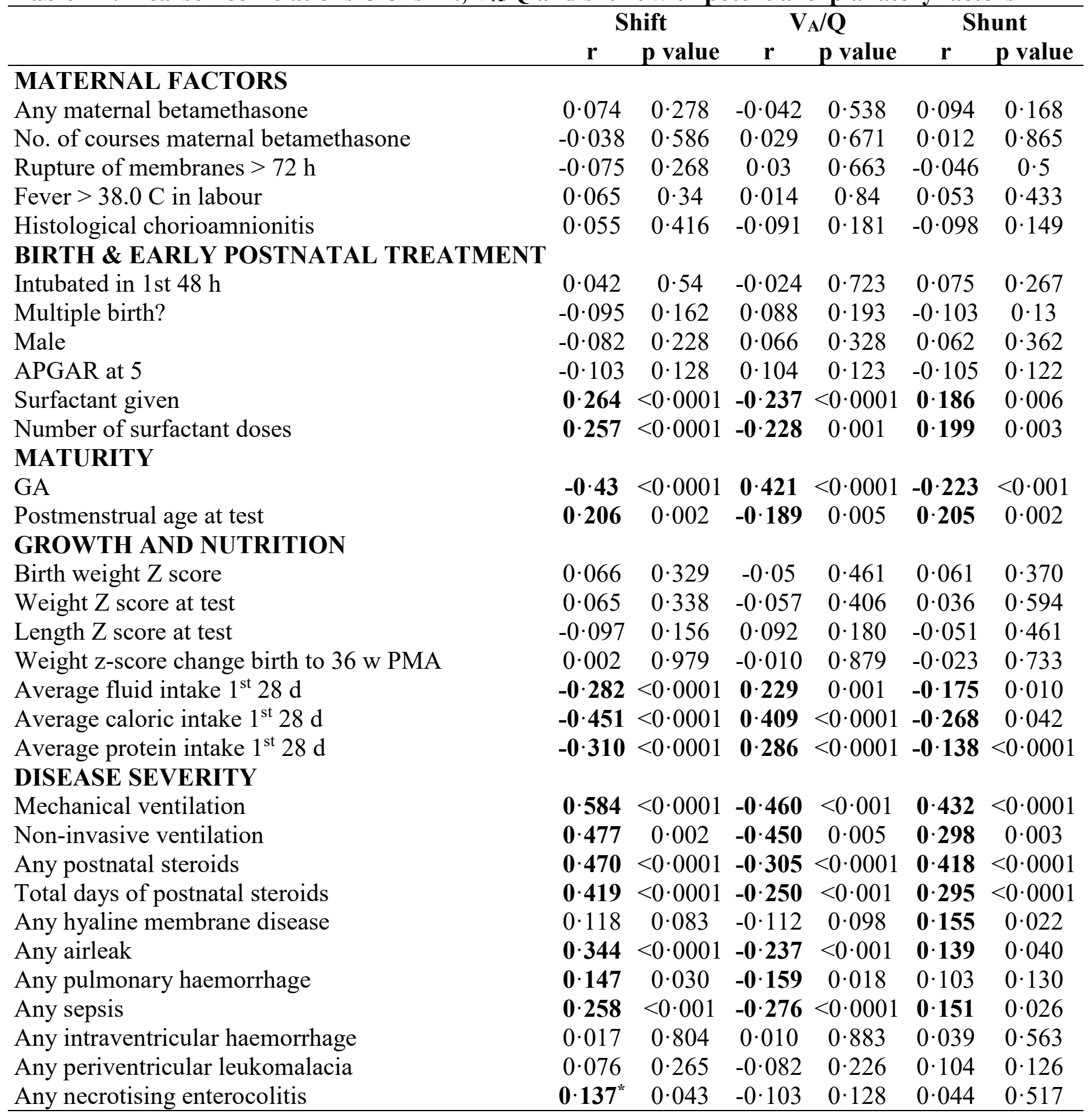

$\mathrm{V}_{\mathrm{A}} / \mathrm{Q}$ - ventilation perfusion; PMA - postmenstrual age. Significant correlations are in bold font. 
Table E5: Rotated Principal Components Analysis Matrix

\begin{tabular}{|c|c|c|c|c|}
\hline & \multicolumn{4}{|c|}{ Component } \\
\hline Right shift & 1 & 2 & 3 & 4 \\
\hline Duration of ventilation* & $0 \cdot 864$ & $-0 \cdot 200$ & $0 \cdot 105$ & $-0 \cdot 082$ \\
\hline Any postnatal steroids & $0 \cdot 817$ & $-0 \cdot 096$ & $-0 \cdot 207$ & $-0 \cdot 005$ \\
\hline Any airleak & $0 \cdot 701$ & $-0 \cdot 034$ & $-0 \cdot 196$ & 0.063 \\
\hline Average fluid intake $1^{\text {st }} 28 \mathrm{~d}$ & $0 \cdot 062$ & $0 \cdot 767$ & $0 \cdot 062$ & $-0 \cdot 146$ \\
\hline Average protein intake $1^{\text {st }} 28 \mathrm{~d}$ & $-0 \cdot 067$ & $0 \cdot 748$ & $0 \cdot 337$ & $0 \cdot 110$ \\
\hline Average caloric intake $1^{\text {st }} 28 \mathrm{~d}$ & $-0 \cdot 251$ & $0 \cdot 639$ & $0 \cdot 593$ & $0 \cdot 047$ \\
\hline Any NEC & $0 \cdot 109$ & $-0 \cdot 528$ & $0 \cdot 185$ & 0.059 \\
\hline Any S & $0 \cdot 237$ & $-0 \cdot 467$ & $-0 \cdot 367$ & $-0 \cdot 067$ \\
\hline Gesta & $-0 \cdot 156$ & $0 \cdot 124$ & $0 \cdot 858$ & $0 \cdot 060$ \\
\hline Any s & $0 \cdot 012$ & $-0 \cdot 012$ & $-0 \cdot 774$ & $0 \cdot 157$ \\
\hline Postmenstru & $0 \cdot 313$ & $-0 \cdot 123$ & $-0 \cdot 158$ & $0 \cdot 738$ \\
\hline n-invasive venti & $-0 \cdot 495$ & $-0 \cdot 204$ & $-0 \cdot 099$ & 0.673 \\
\hline Any pulmons & $0 \cdot 127$ & $-0 \cdot 341$ & $-0 \cdot 214$ & $-0 \cdot 464$ \\
\hline \multicolumn{5}{|l|}{$\mathbf{V}_{\mathrm{A}} / \mathbf{Q}$} \\
\hline Durati & $0 \cdot 870$ & $-0 \cdot 198$ & $-0 \cdot 146$ & $-0 \cdot 077$ \\
\hline Any $p$ & $0 \cdot 818$ & $-0 \cdot 115$ & $0 \cdot 193$ & $-0 \cdot 011$ \\
\hline Any ai & $0 \cdot 70$ & $-0 \cdot 038$ & $0 \cdot 202$ & $0 \cdot 052$ \\
\hline Average fluid intake $1^{\text {st }} 28 \mathrm{~d}$ & $0 \cdot 037$ & $0 \cdot 817$ & $-0 \cdot 198$ & 0057 \\
\hline Average protein intake $1^{\text {st }} 28 \mathrm{~d}$ & $-0 \cdot 083$ & $\mathbf{0} \cdot 827$ & $0 \cdot 095$ & $-0 \cdot 210$ \\
\hline Average caloric intake $1^{\text {st }} 28 \mathrm{~d}$ & $-0 \cdot 259$ & $0 \cdot 713$ & $-0 \cdot 503$ & $0 \cdot 014$ \\
\hline Any Sepsis & $0 \cdot 238$ & $-0 \cdot 484$ & $0 \cdot 338$ & $-0 \cdot 054$ \\
\hline Gestation & $-0 \cdot 148$ & $0 \cdot 217$ & $-0 \cdot 852$ & 0.065 \\
\hline Any surfactant & $0 \cdot 006$ & $-0 \cdot 085$ & $0 \cdot 782$ & $0 \cdot 149$ \\
\hline Postmenstrual age at test & $0 \cdot 324$ & $-0 \cdot 091$ & $0 \cdot 160$ & $0 \cdot 736$ \\
\hline Duration of non-invasive ventilation & $-0 \cdot 482$ & $-0 \cdot 184$ & $0 \cdot 078$ & 0.691 \\
\hline Any pulmonary haemorrhage & $0 \cdot 123$ & $-0 \cdot 377$ & $0 \cdot 181$ & $-0 \cdot 451$ \\
\hline
\end{tabular}

\section{Shunt}

\begin{tabular}{l|c|c|c|c}
\hline Duration of ventilation* & $\mathbf{0} \cdot \mathbf{8 8 0}$ & $-0 \cdot 167$ & $-0 \cdot 096$ & $0 \cdot 120$ \\
\hline Any postnatal steroids & $0 \cdot 810$ & $-0 \cdot 154$ & $0 \cdot 138$ & $0 \cdot 110$ \\
\hline Any airleak & $0 \cdot 677$ & $-0 \cdot 092$ & $0 \cdot 147$ & $0 \cdot 038$ \\
\hline Duration of non-invasive ventilation* & $-0 \cdot 648$ & $-0 \cdot 138$ & $-0 \cdot 092$ & $0 \cdot 533$ \\
\hline Average protein intake $1^{\text {st }} 28 \mathrm{~d}$ & $-0 \cdot 071$ & $\mathbf{0} \cdot \mathbf{8 5 1}$ & $-0 \cdot 132$ & $0 \cdot 089$ \\
\hline${\text { Average caloric intake } 1^{\text {st }} 28 \mathrm{~d}}^{\text {Average fluid intake } 1^{\text {st }} 28 \mathrm{~d}}$ & $-0 \cdot 287$ & $0 \cdot 782$ & $-0 \cdot 329$ & $-0 \cdot 091$ \\
\hline Any Sepsis & $0 \cdot 058$ & $0 \cdot 774$ & $0 \cdot 225$ & 0019 \\
\hline Number of surfactant doses & $0 \cdot 213$ & $-0 \cdot 553$ & $0 \cdot 310$ & $-0 \cdot 001$ \\
\hline Gestation & $0 \cdot 013$ & $-0 \cdot 001$ & $0 \cdot 784$ & $0 \cdot 033$ \\
\hline Postmenstrual age at test & $-0 \cdot 208$ & $0 \cdot 378$ & $\mathbf{- 0 \cdot 6 7 7}$ & $-0 \cdot 148$ \\
\hline Any hyaline membrane disease & $0 \cdot 193$ & $-0 \cdot 059$ & $-0 \cdot 002$ & $\mathbf{0} \cdot \mathbf{8 5 2}$ \\
\hline
\end{tabular}

*unstandardized residual versus gestation; rotation method varimax with Kaiser normalization. Bold font indicates significant factor used for multivariable linear regression. 